\title{
Utilização de Polímero Reciclável como Peça de Transmissão de Carga
}

\author{
Paulo M. F. Viana, Lara C. B. de Oliveira \& Mário S. J. dos Santos
}

A utilização de materiais recicláveis na Engenharia tem sido crescente, principalmente nos últimos anos. Diversos produtos como pisos, blocos e revestimentos têm sido utilizados como materiais reciclados por serem de fácil aplicação, resistentes, econômicos e ambientalmente sustentáveis. Este trabalho objetiva verificar a possibilidade de utilização de materiais recicláveis de Polietileno de Alta Densidade - PEAD como peças de transmissão de carga, tais como vigas baldrame e blocos. Para tanto, foram realizados ensaios de resistência no laboratório de Engenharia Civil da Universidade Estadual de Goiás onde foi verificada a performance da aplicação.

Palavras-chave: reciclagem; PEAD; materiais alternativos.

The use of recyclable materials in engineering has been growing, especially in recent years. Various products such as tiles, blocks and coatings have been utilized like recycled materials because they are easy to use, durable, economical and environmentally sustainable. This paper aims to verify the use of recyclable materials from the Polyethylene - high density - HDPE in structures such as beams and blocks. Thus were performed tests in the Civil Engineering Laboratory of the University of State of Goias where was verified the performance of the application.

Keywords: recycling; HDPE; alternative materials. 


\section{Introdução}

O consumo crescente de bens não duráveis e a concentração das populações nos centros urbanos alavancaram a problemática da disposição final dos resíduos sólidos. Segundo dados do $\mathrm{IBGE}^{1}$ a produção de Resíduos Sólidos Urbanos - RSU ${ }^{2,3}$ no Brasil supera 170 mil toneladas/dia, sendo: $47 \%$ destinada a aterros sanitários, $23,3 \%$ aterros controlados, 30,5\% em lixões e $0,4 \%$ selecionados em triagem e $0,1 \%$ incinerados. Cerca de $60 \%$ dos municípios brasileiros ainda dispõem os RSU em lixões. A problemática é intensificada caso se considere a taxa de reciclagem dos produtos dos RSU, que na maioria dos casos, não supera $15 \%{ }^{4}$. A Figura 1 apresenta a distribuição em pesos percentuais dos resíduos sólidos urbanos no Brasil.

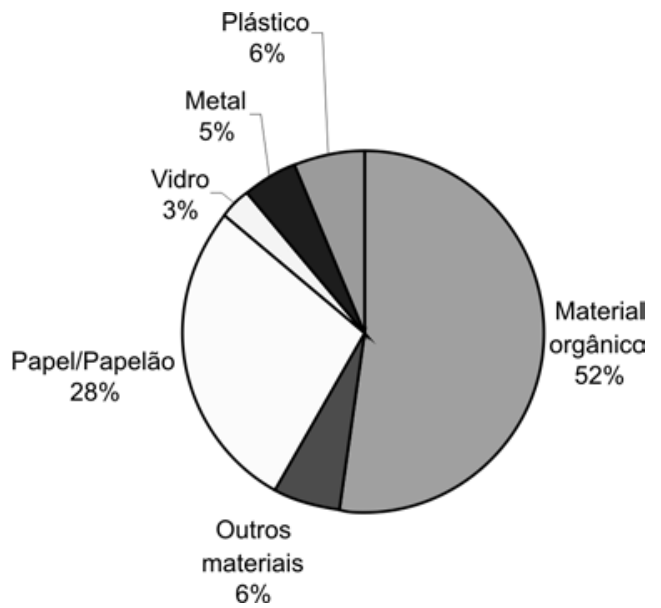

Figura 1: Distribuição dos materiais que compõem o resíduo sólido urbano brasileiro 5 .

Considerando os plásticos, o Brasil recicla cerca de $20 \%$ de todo o material (aproximadamente 2,2 milhões de toneladas/ano de material reciclado). Destes, $7 \%$ representam a quantidade reciclada no Centro-Oeste6. Segundo Associação Brasileira de Recicladores de Materiais Plásticos - ABREMPLAST 60\% deste material provêm de resíduos industriais e $40 \%$ do lixo urbano.

Apesar da porcentagem dos plásticos parecer pequena ( $6 \%$ do resíduo sólido urbano brasileiro) deve-se considerar que este material ocupa grandes volumes em aterros, o que pode contribuir para contaminar o solo e liberar gases poluentes quando incinerados. É de extrema importância o processo de reciclagem. Neste contexto, qualquer contribuição no sentido de apresentar soluções de emprego ao material reciclado será muito bem-vinda.

Os materiais denominados plásticos são artefatos de resinas sintéticas produzidas a partir de matérias-primas de origem natural, como o petróleo, o gás natural, o carvão ou o sal comum. Apesar da grande produção de "plásticos", estes consomem menos de $4 \%$ do petróleo produzido comercialmente. Os plásticos são constituídos de macromoléculas denominadas polímeros que dependendo da sua composição (monômeros) apresentam diferentes propriedades físicas e químicas. A estrutura polimérica depende do método de polimerização empregado ${ }^{7,8}$.

Nos RSU os plásticos mais freqüentes são: o Polietileno - de alta densidade (PEAD) ou de baixa densidade (PEBD) - com 37\% e o PET (polietileno tereftalato) com 21\%. Outros polímeros, como o PVC (policloreto de vinila), o PP (polipropileno) e o PS (poliestireno) também figuram entre os resíduos. A Figura 2 apresenta a distribuição média dos plásticos encontrados no volume total de resíduo disposto no Brasil.

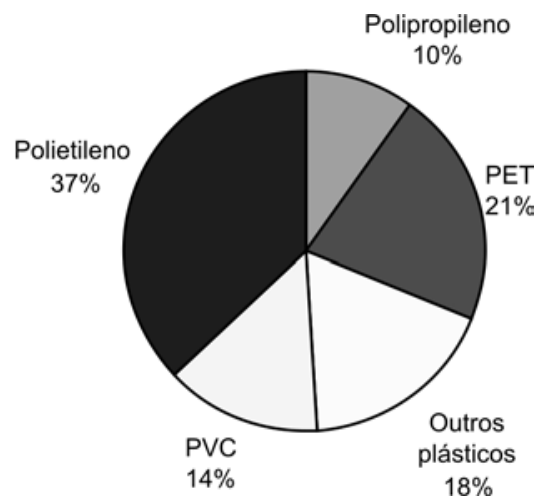

Figura 2: Distribuição média dos plásticos encontrados no volume total de resíduo disposto9.

Há certo receio quanto à qualidade técnica dos materiais reciclados porque algumas propriedades podem ser alteradas nos sucessivos ciclos de vida a que estão submetidos. A tendência, então, é empregar tais materiais em produtos de utilização menos nobre. Porém, é importante salientar que o vidro, o alumínio e alguns plásticos mantêm suas características praticamente inalteradas ao serem reciclados ${ }^{10}$. 
Este trabalho apresenta um estudo relativo à utilização de material reciclado de Polietileno de Alta Densidade - PEAD como peças de transmissão de carga (elementos estruturais isolados) utilizados em fundações tais como: vigas baldrames e blocos. Para tanto, foram confeccionados corpos de prova a partir de material produto da reciclagem mecânica seguindo as etapas de: moagem, lavagem, secagem, extrusão e granulação9. O principal objetivo foi de verificar a resistência à tração, compressão e flexão das peças, bem como a deformação lenta (fluência) de modo que fosse avaliada a performance do material alternativo como elemento transmissor de carga.

\section{Metodologia}

A metodologia empregada neste trabalho consiste na montagem, execução, registro/coleta e interpretação de dados de ensaios de compressão ${ }^{11}$, tração ${ }^{12}$, tração na flexão ${ }^{13}$ e deformação lenta realizados no laboratório de Engenharia da Universidade Estadual de Anápolis - UEG/UnUCET. Para tanto, utilizou-se dos seguintes materiais: corpo de prova de PEAD-C com inclusões de PEBD, PVC, PET e PP em porcentagens aleatórias (onde: $\mathrm{C}=$ Compostos com porcentagem $>50 \%$ de PEAD), prensa universal, pórtico de aplicação de cargas, sistema de registro de leituras baseado no método fotográfico de leitura das deformações do CP. A Figura 3 apresenta o esquema típico dos ensaios realizados.

\section{OS CORPOS DE PROVA - MATERIAL RECICLADO}

Estudos realizados com CPs de plásticos reciclados (plásticos compostos pela mistura de PEBD, PEAD, PP e PS) originaram materiais com propriedades semelhantes ao $\mathrm{PEAD}^{14}$, com vantagem de serem mais resistentes à flexão. A temperatura de injeção não influencia significativamente nas propriedades mecânicas avaliadas na faixa de 180 a $190^{\circ} \mathrm{C}$ e que na temperatura de $200^{\circ} \mathrm{C}$ já há indícios de degradação do material. Portanto, os plásticos obtidos de artefatos descartáveis, potencialmente recicláveis, resultam em um material leve, resistente e de baixo custo, podendo competir com os termoplásticos virgens em diversas aplicações". ${ }^{14}$

Baseado nestas premissas foram moldados corposde-prova com material reciclado de PEAD-C. Para os ensaios de compressão e tração foram utilizados CPs de $70 \mathrm{~mm}$ de diâmetro $140 \mathrm{~mm}$ de altura, para os ensaios de flexão CPs de 150x150x150mm e Fluência de 200,72mm de comprimento, $51,47 \mathrm{~mm}$ de largura, $99,60 \mathrm{~mm}$ de altura.

O PEAD é um termoplástico, com utilização, em material hospitalar, lacres de embalagens e recipientes para embalagens de produtos de limpeza ${ }^{7}$. A Figura 4 apresenta a sua estrutura molecular que permanece estável durante o processo de reciclagem. A Figura 5 apresenta corpos de prova típicos utilizados nos ensaios de resistência a tração e compressão.

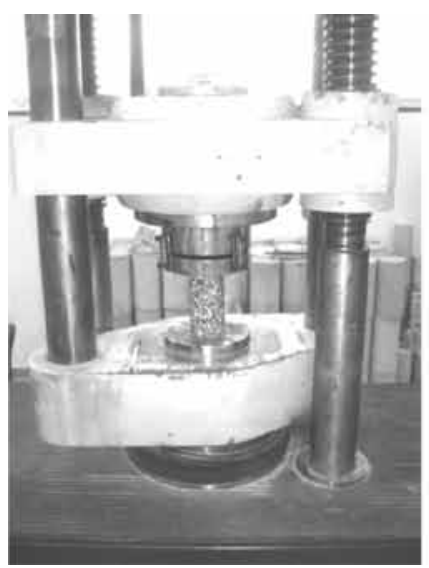

(a)

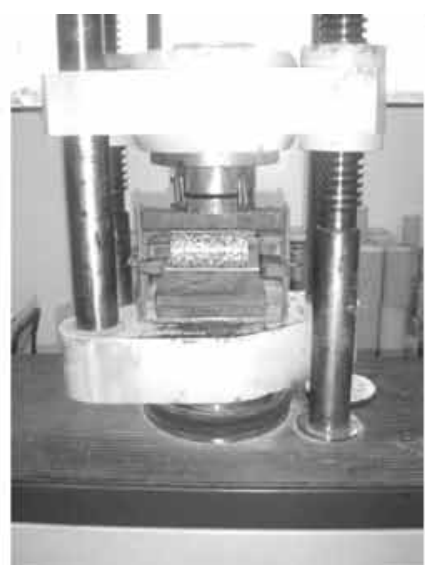

(b)

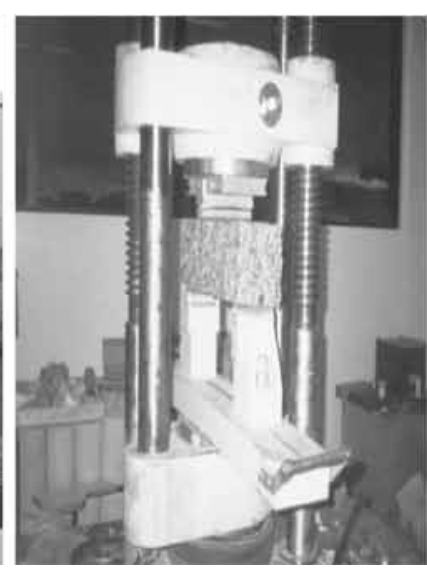

(c)

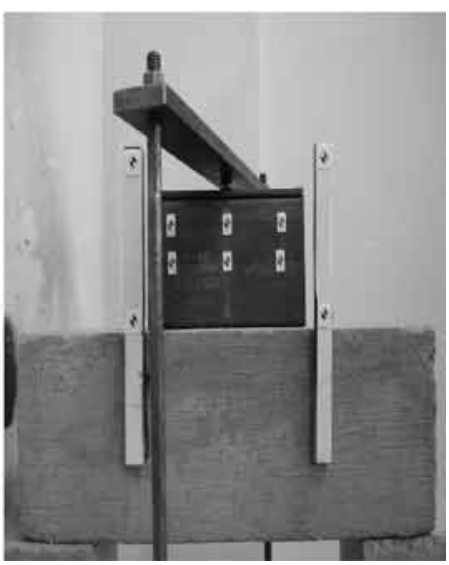

(d)

Figura 3: Ensaios realizados: (a) Compressão simples, (b) Tração, (c) Flexão e (d) Deformação lenta. 
As principais propriedades físicas do PEAD são: Peso molecular: $200.000 \mathrm{~g} / \mathrm{mol}$, Densidade: $0.94-0.97 \mathrm{~g} /$ $\mathrm{ml}$, Temperatura de fusão cristalina $\mathrm{Tm}=130-135^{\circ} \mathrm{C}$, Temperatura de transição vítrea $\mathrm{Tg}=100-125^{\circ} \mathrm{C}$, Índice de refração $=1.54$, e Cristalinidade $=95 \%$.

Ainda, como características relevantes à alta resistência química e a solventes; o baixo coeficiente de atrito (macio e flexível), a facilidade do processamento, as características isolantes, a baixa permeabilidade à água, o fato de ser um matérial atóxico e inodoro e o baixo custo creditam o material em relação a sua aplicabilidade ${ }^{17}$.

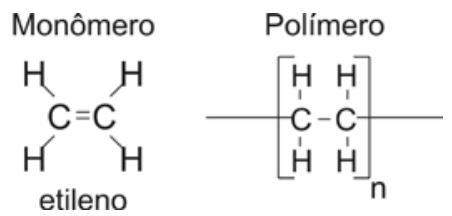

Figura 4: Estrutura Molecular do PEAD.

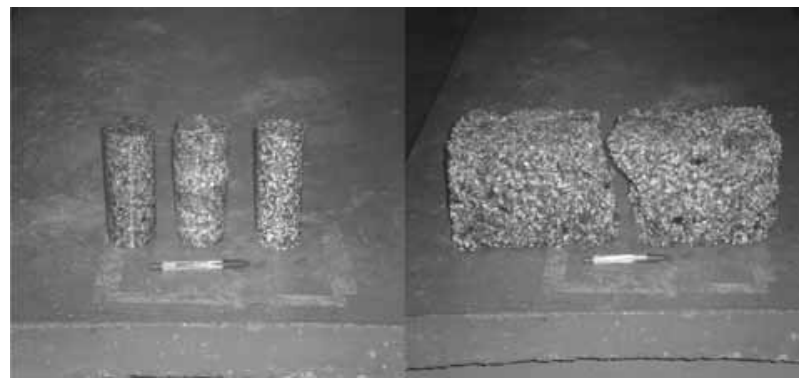

Figura 5: CPs utilizados nos ensaios.(a) Ensaios de compressão e tração e (b) Ensaios de flexão (após ruptura).

\section{Resultados e Discussão}

\section{RESISTÊNCIA À COMPRESSÃO}

A Tabela 1 apresenta os resultados dos ensaios de resistência à compressão ${ }^{11}$. A Figura 6 apresenta a forma de ruptura dos corpos de prova.

Pode-se verificar nos resultados apresentados na tabela 1 que os valores de resistência à compressão - RC são semelhantes ao de uma peça de concreto, material usualmente empregado na confecção de peças de fundação. Em termo médios a RC das peças de PEAD-C foi de $\mathrm{RC}=19,5 \mathrm{MPa}$, ou seja 2,5\% inferior ao valor de $20 \mathrm{MPa}$ e $30 \%$ superior ao valor de $15 \mathrm{MPa}$. O tipo de ruptura destas peças usualmente é o cisalhamento. A posição da superfície de ruptura depende da estrutura do material e do estado de tensões no interior da peça, podendo apresentar variações. Um outro fator que deve ser considerado é o processo de moldagem sendo que caso haja imperfeições iniciais a peça poderá romper por esmagamento, caso dos CP-02 e CP-04 e apresentar resistências inferiores.

Tabela 1: Resultados dos ensaios de resistência à compressão.

\begin{tabular}{|c|c|c|c}
\hline $\begin{array}{c}\text { Identificação } \\
\text { (na sequência dos ensaios) }\end{array}$ & Idade do CP & $\begin{array}{c}\text { Resistência à } \\
\text { compressão (MPa) }\end{array}$ & $\begin{array}{c}\text { Resistência típica } \\
\text { do concreto para peças } \\
\text { de fundação (MPa) }\end{array}$ \\
\hline $\mathrm{CP}-05$ & 06 dias & 20,1 & $15-20$ \\
\hline $\mathrm{CP}-06$ & 06 dias & 19,8 & $15-20$ \\
\hline $\mathrm{CP}-07$ & 13 dias & 23,3 & $15-20$ \\
\hline $\mathrm{CP}-08$ & 13 dias & 18,0 & $15-20$ \\
\hline $\mathrm{CP}-01$ & 18 dias & 19,1 & $15-20$ \\
\hline $\mathrm{CP}-02$ & 18 dias & 17,6 & $15-20$ \\
\hline $\mathrm{CP}-09$ & 27 dias & 21,3 & $15-20$ \\
\hline $\mathrm{CP}-10$ & 27 dias & 20,4 & $15-20$ \\
\hline $\mathrm{CP}-03$ & 29 dias & 19,4 & $15-20$ \\
\hline $\mathrm{CP}-04$ & 29 dias & 16,1 & \\
\hline & & & 150 \\
\hline
\end{tabular}

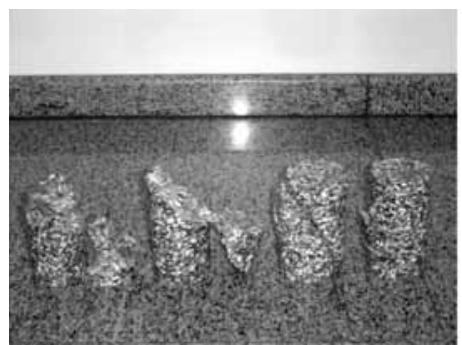

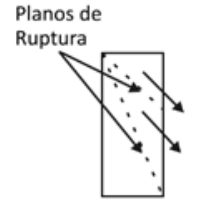

(a)

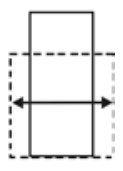

(b)
Figura 6: Tipos de Ruptura característica: (a) Cisalhamento, (b) Esmagamento.

\section{RESISTÊNCIA À TRAÇÃO POR COMPRESSÃO DIAMETRAL}

A Tabela 2 apresenta os resultados dos ensaios de resistência à tração ${ }^{12}$. A Figura 7 apresenta a forma de ruptura dos corpos de prova.

Como apresentado na Tabela 2 pode-se verificar que a resistência à tração - RT dos CP de PEAD-C são superiores a resistência à tração do concreto. Em média os valores de RT da peças de PEAD-C foram de 3,7 MPa o que equivale um valor de $85 \%$ superior ao valor das peças de concreto de 2,0 MPa. Isto significa menos necessidade de inclusões de aço nas peças, ou ainda a eliminação da 
armadura caso o esforço de tração esperado seja inferior ao disponível na peça. O tipo de ruptura apresentado é idêntico ao obtido em peças de concreto.

Tabela 2: Resultados dos ensaios de resistência à tração

\begin{tabular}{|c|c|c|c|}
\hline $\begin{array}{c}\text { Identificação } \\
\text { (na sequência dos ensaios) }\end{array}$ & Idade do CP & $\begin{array}{c}\text { Resistência à } \\
\text { tração }(\mathrm{MPa})\end{array}$ & $\begin{array}{c}\text { Resistência típica do } \\
\text { concreto para peças } \\
\text { de fundação (MPa) }\end{array}$ \\
\hline $\mathrm{CP}-05$ & 06 dias & 3,06 & $1,5-2,0$ \\
\hline $\mathrm{CP}-06$ & 06 dias & 3,37 & $1,5-2,0$ \\
\hline $\mathrm{CP}-08$ & 13 dias & 3,60 & $1,5-2,0$ \\
\hline $\mathrm{CP}-02$ & 18 dias & 4,11 & $1,5-2,0$ \\
\hline $\mathrm{CP}-09$ & 27 dias & 3,41 & $1,5-2,0$ \\
\hline $\mathrm{CP}-10$ & 27 dias & 3,75 & $1,5-2,0$ \\
\hline $\mathrm{CP}-03$ & 29 dias & 3,97 & $1,5-2,0$ \\
\hline $\mathrm{CP}-04$ & 29 dias & 4,15 & $1,5-2,0$ \\
\hline
\end{tabular}

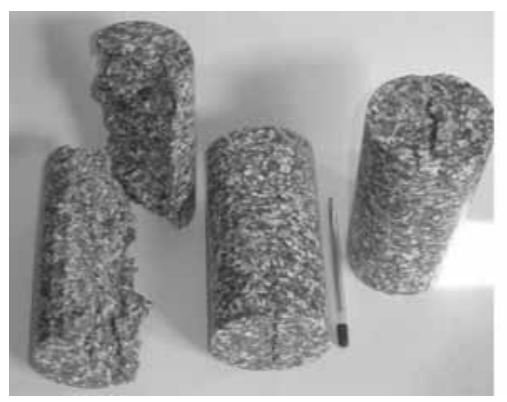

Plano de Ruptura - Fissura Vertical

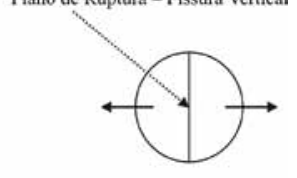

Figura 7: Tipo de Ruptura característica: Fissura vertical devido compressão diametral.

\section{RESISTÊNCIA À TRAÇÃO POR COMPRESSÃO DIAMETRAL}

A Tabela 3 apresenta o resultado do ensaio de resistência à tração na flexão $^{13}$ em corpo-de-prova prismático. A Figura 8 apresenta a forma de ruptura dos corpos de prova.

Tabela 3: Resultado do ensaio de resistência à tração na flexão.

\begin{tabular}{|c|c|c|}
\hline $\begin{array}{c}\text { Identificação } \\
\text { (na sequência dos ensaios) }\end{array}$ & $\begin{array}{c}\text { Resistência à tração } \\
\text { (Mpa) }\end{array}$ & $\begin{array}{c}\text { Resistência típica do } \\
\text { concreto para peças } \\
\text { de fundação (Mpa) }\end{array}$ \\
\hline $\mathrm{CP}-01$ & $4,50 \mathrm{Mpa}$ & $1,5-2,0$ \\
\hline
\end{tabular}

$\mathrm{O}$ resultado apresentado na tabela 3 confirma que o valor a tração das peças de PEAD-C são superiores aos valores do concreto, entretanto, como não foram realizados ensaios suficientes serão considerados somente os resultados dos ensaios em corpos cilíndricos.

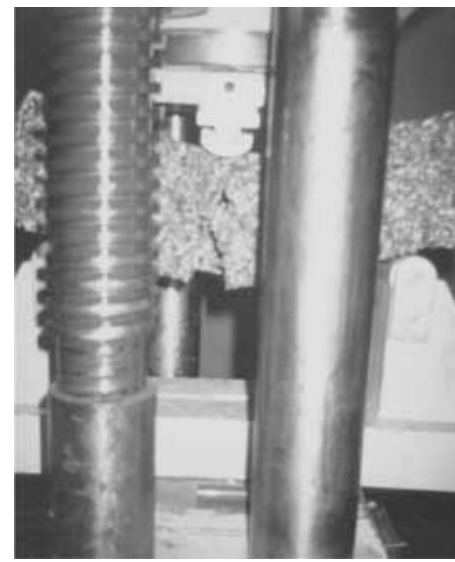

Plano de Ruptura - Fissura Vertical

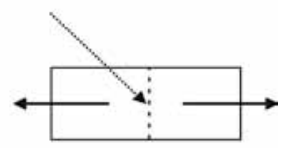

Figura 8: Tipo de Ruptura característica: Fissura vertical devido compressão.

\section{MÓDULO DE ELASTICIDADE DO MATERIAL}

Uma propriedade importante nos elementos transmissores de carga é o Módulo de Elasticidade - E. Para tanto, foram realizados ensaios adicionais para a determinação do EPEAD-C. A determinação do módulo de deformação estática, à compressão axial simples, foi realizada em corpos-de-prova moldados de forma cilíndrica $^{18}$. Os resultados obtidos para EPEAD-C a compressão foram de aproximadamente $0,6 \mathrm{Gpa}$. $\mathrm{O}$ valor obtido para EPEAD-C corresponde cerca de $2,4 \%$ do valor do Econcreto $\stackrel{\sim}{=} 25 \mathrm{GPa}$. Considerando a aplicação do material alternativo como elemento transmissor de carga devem-se considerar estudos adicionais, principalmente em relação à fluência do material quando submetido a solicitações típicas de obra.

\section{DEFORMAÇÕES LENTAS - FLUÊNCIA}

Para realizar o ensaio de fluência foi moldado um corpo de prova de uma peça de PEAD-C. O CP foi devidamente instalado sobre um sistema de aplicação de cargas, conforme Figura 9.

O sistema de aplicação de cargas constitui-se de um pórtico de aço rígido com esfera centralizadora e com capacidade de aplicar um carregamento concentrado de até $1,2 \mathrm{kN}$. Para simular a carga estática de uma parede foi utilizado um carregamento concentrado de $0,6 \mathrm{kN}$ distribuído sobre uma área de $100 \mathrm{~cm}^{2}(\sigma=60 \mathrm{kPa})$.

Para registrar as deformações da peça foi utilizado o método fotográfico ${ }^{15}$. Este método vem sendo utilizado 
em diversos trabalhos ${ }^{16}$. Neste modelo de leitura, inicialmente conhece-se a posição real de pontos que definem um plano (referência global). A amostra está contida dentro deste plano. Mediante referências, pode-se conhecer a posição real de qualquer ponto presente numa imagem a ser trabalhada através de um fator de escala obtido de um sistema de equações escrito em função das coordenadas locais dos pontos de leitura medidas na foto e das coordenadas dos marcos de referência do sistema global ${ }^{16}$. Pode-se utilizar um programa associado em planilha eletrônica para obter os resultados das deformações obtidas por meio do registro fotográfico ${ }^{16}$.

Para realizar os ensaios, inicialmente aplicou-se o carregamento tendo com referencia a leitura padrão sem carregamento. As leituras foram registradas durante 4 meses mediante fotografia digitalizada. Foram instalados 6 (seis) pontos de leitura lateral (a,b,c,d,e e f) e 4 (quatro) de leitura frontal (a,b,c e d).

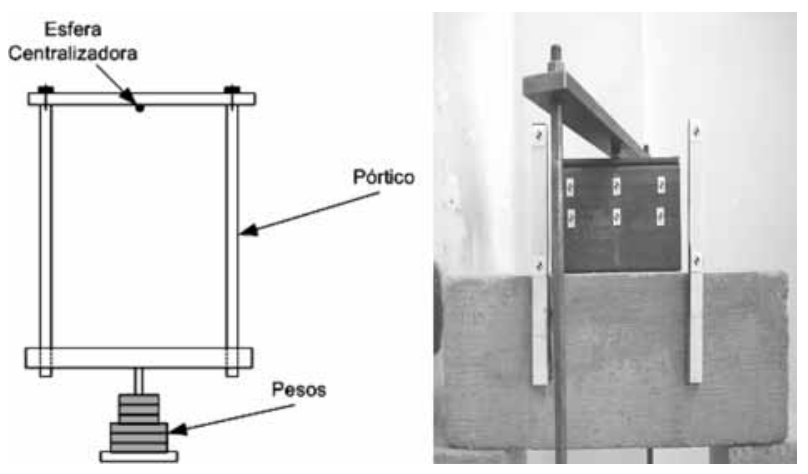

Figura 9: Sistema de aplicação de cargas.

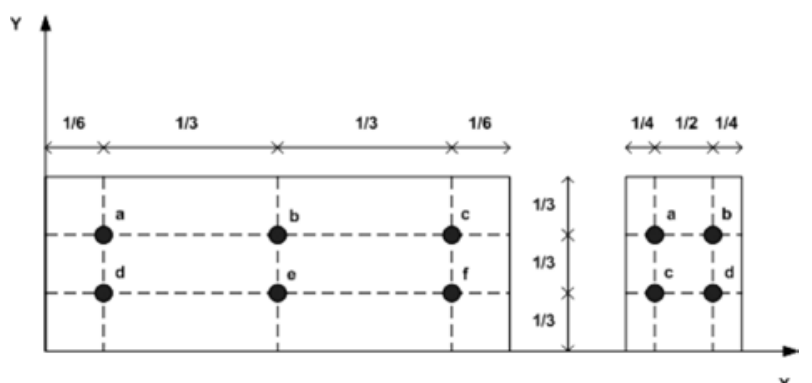

Figura 10: Pontos de leitura: (a) Seção lateral e (b) Seção frontal

Na seção lateral, o ponto a refere-se ao canto superior esquerdo do corpo de prova e o f ao canto inferior direito. A Figura 11 apresenta a deformação vertical média dos pontos em relação ao plano horizontal (eixo X) do corpo de prova - vista lateral.

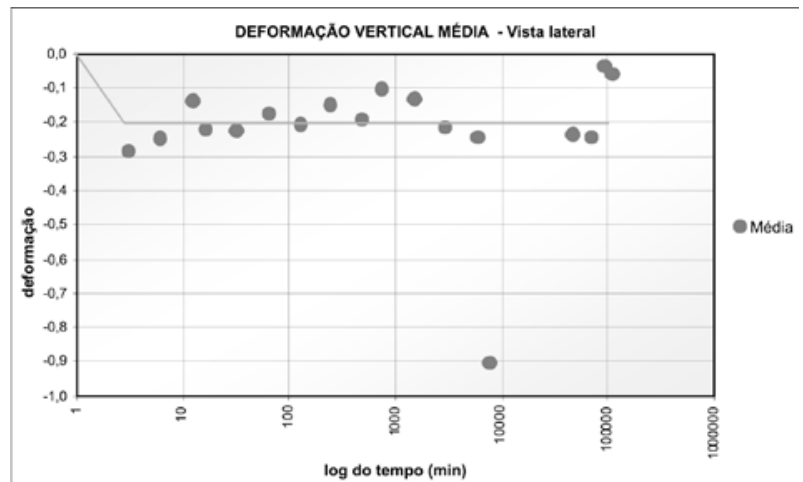

Figura 11: Deformação vertical média dos pontos em relação ao plano horizontal do corpo de prova - vista lateral.

Pode-se observar na Figura 11 que a deformação vertical máxima média foi da ordem de 0,2 para a maioria dos pontos. $\mathrm{O}$ ponto próximo à leitura de 10.000 min constitui-se provavelmente como um erro de leitura. Considerando que a leitura das deformações $\underline{\underline{y}}$ praticamente não variou pode-se concluir que $o^{y}$ corpo de prova não apresentou fluência nesta direção, considerando o carregamento aplicado. A Figura 12 apresenta a deformação vertical média dos pontos em relação ao plano horizontal do corpo de prova - vista frontal.

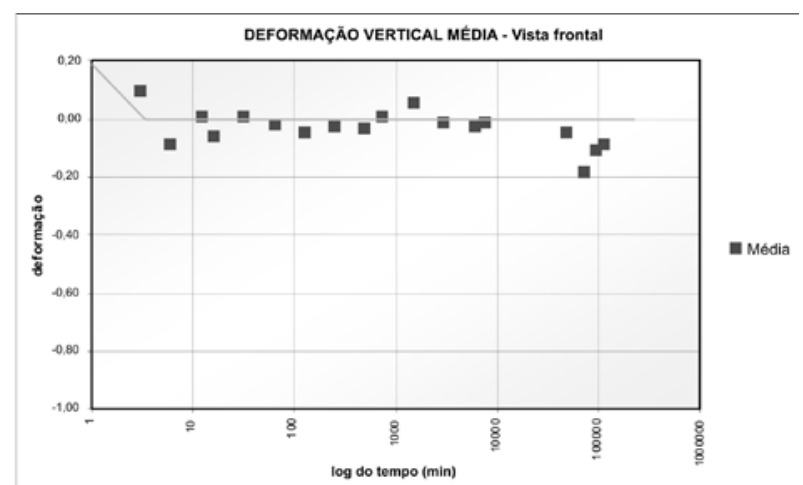

Figura 12: Deformação vertical média dos pontos em relação ao plano horizontal do corpo de prova - vista frontal

Pode-se observar na Figura 12 que praticamente não ocorreu deformação vertical frontal para a maioria dos postos. Pode-se concluir que o corpo de prova não apresentou fluência nesta direção, considerando o 
carregamento aplicado.

De fato, considerando o comportamento rígido do material, a faixa de carregamento utilizado não mobilizou deformações significativas. Como exemplo, considerando um módulo de elasticidade de aproximadamente $\mathrm{E}=600$ $\mathrm{Mpa}(0,6 \mathrm{GPa})$ têm-se, para um carregamento de $\sigma=60$ KPa uma deformação de $0,0001 \cong 0,0$ o que confere com os valores registros nos ensaios.

\section{Conclusão}

Considerando os resultados apresentados no artigo pode-se concluir que:

a) Materiais reciclados de PEAD-C podem ser utilizados como peças de transmissão de carga, tais como vigas baldrame, blocos e estacas;

b) A resistência à compressão dos corpos de provas ensaiados foi similiar a resistência típica do concreto para aplicações em pequenas edificações;

c) A resistência à tração dos corpos de provas ensaiados foi superior à resistência típica do concreto para aplicações em pequenas edificações;

d) Para os carregamentos aplicados à peça de material de PEAD-C não apresentou fluência.

\section{BIBLIOGRAFIA}

1. Instituto Brasileiro de Geografia e Estatística - IBGE. Disponível em: <www.ibge.gov.br>. Acesso em: 23 fev. 2004.

2. Associação Brasileira de Normas Técnicas ABNT/ NBR 10004. Resíduos sólidos - Classificação, 2004.

3. Associação Brasileira de Normas Técnicas ABNT/ NBR 8849. Apresentação de projetos de aterros controlados de resíduos sólidos urbanos, 1985.

4. Ambiente Brasil.; Ambiente: resíduos. Disponível em: http://www.ambientebrasil.com.br. Acesso em: 25/08/2008.

5. Anon, M.C.; Curso Básico Intensivo de Plásticos (C.B.I.P). Jornal de Plásticos, Niterói, 1997.

6. Compromisso Empresarial para Reciclagem
- CEMPRE. Ficha Técnica - Plástico Rígido. Disponível em: http://www.cempre.org.br/fichas_ tecnicas.php?lnk=ft_plastico_rigido.php Acesso em : 23/07/2007.

7. Mano, E. B.; Polímeros como Materiais de Engenharia. Edgard Blucher: São Paulo, 1991;

8. Franchetti, S. M.; Marconato, L. C.; Química Nova na Escola. 2003, 18, 4.

9. Wiebeck, H.; Reciclagem Mecânica do PVC: Uma Oportunidade de Negócio. USP: São Paulo, 1999.

10. Bidone, F. R. A.; Conceitos Básicos de Resíduos Sólidos, EESC/USP: São Carlos, 1999.

11. Associação Brasileira de Normas Técnicas. ABNT/ NBR 5739. Concreto - Ensaio de compressão de corpo-de-prova cilíndricos, 2007.

12. Associação Brasileira de Normas Técnicas. ABNT/ NBR 7222. Argamassa e concreto - Determinação da resistência à tração por compressão diametral de corpo-de-prova cilíndricos, 1994.

13. Associação Brasileira de Normas Técnicas. ABNT/ NBR 12142. Concreto - Determinação da resistência à tração na flexão em corpo-de-prova prismáticos, 1991.

14. Caraschi, J. C.; Leão, A. L.; Acta Scientiarum. 2002, 24 (6), 1599.

15. Bueno, B. S.; Thesis - University of Leeds, Leeds, 1987.

16. Costanzi, M. A; Bueno, B. S; Barras, L. C. S, Zornberg, J.G.; Revista Solos e Rochas. 2003, 26, (3), 12.

17. Gorni, A. A.; Revista Plástico Industrial, 2003 Disponível em: <www.gorni.eng.br/intropol.html>. Acesso em: 25/03/2005;

18. Associação Brasileira de Normas Técnicas. ABNT/ NBR 7222. Concreto - Determinação dos módulos estáticos de elasticidade e de deformação e da curva tensão-deformação, 2008. 


\section{Artigo 4}

Paulo M. F. Viana ${ }^{*}$, Lara C.

B. de Oliveira'

e Mário S. J. dos Santos'

1 Curso de Engenharia Civil. Universidade Estadual de Goiás

- UnUCET/UEG. Rodovia BR153, Arco Verde, 750001-970 Anápolis, GO, Brasil.

*E-mail: paulo.viana@ueg.br 